\title{
MEASUREMENT OF THE POWERTRAIN TORQUE
}

\author{
P. Kučera*, V. Píštěk ${ }^{* *}$, A. Prokop ${ }^{* * *}$, K. Řehák ${ }^{\dagger}$
}

\begin{abstract}
The article deals with evaluation of the torque on a truck with $8 x 8$ drive. This torque was measured by noncontact device while driving uphill. Its mean value was compared with the vehicle simulation results. For this purpose, developed library with blocks for creating computational model of the vehicle and simulation of driving was used. The complete computational model of the vehicle is assembled in the Simulink software. This article continues on the first study of the powertrain where there was a vibration problem. Therefore, it was necessary to analyse the torque and torsional vibrations.
\end{abstract}

Keywords: measurement, torque, FFT, simulink, truck computational model

\section{Introduction}

Vibrations are an integral part of every vehicle and their intensity affects not only passengers but also the life of the powertrain. In practice, a number of tools and methods are used to analyse and limit the vibration. However, some tools are difficult to use on a moving vehicle. Therefore, new methods and tools for vibration and noise analysis are still needed.

This article deals with the analysis of the mean value of the torque of a truck powertrain with a $8 \times 8$ drive. In this case, one of the methods developed to measure the driving torque on a moving vehicle was used. This was a non-contact measurement, and the device will not be described because the manufacturer protects its know-how. The paper focuses primarily on comparing the mean value of the driving torque with the results of the vehicle computational model. This model is assembled from a custom library (Kučera, 2015) with blocks that allows to create different vehicle computational models. The user of this library can simulate vehicle dynamics, test mechatronic systems and analyse vibrations. In this case, a vehicle model with $8 \times 8$ drive was assembled and the driving torque value was monitored when driving uphill. The article describes also an analysis that evaluates torsional vibrations from measured data.

The vibration of the testing vehicle was created above the speed limit set by legislation. Therefore, previously published results of Kučera (2017) show analysis of shaft deflection and their influence on vibrations. Analysis of the driving torque and the resulting torsional vibrations is another step.

\section{Measurement}

Torque measurement was performed on a vehicle with $8 \times 8$ drive. The measuring position was at the longest shaft of the powertrain. It is the shaft which drives the first axle of the vehicle. The measurement position corresponded with the shaft deflection measurement published by Kučera (2017). The measuring

Ing. Pavel Kučera, Ph.D.: Institute of Automotive Engineering, University of Technology, Technická 2896/2; 616 69, Brno; CZ, kucera@fme.vutbr.cz

** Prof. Ing. Václav Píštěk, DrSc.: Institute of Automotive Engineering, University of Technology, Technická 2896/2; 616 69, Brno; CZ, pistek.v@fme.vutbr.cz

*** Ing. Aleš Prokop, Ph.D.: Institute of Automotive Engineering, Univsity of Technology, Technická 2896/2; 616 69, Brno; CZ, prokop.a@fme.vutbr.cz

† Ing. Kamil Řehák: Institute of Automotive Engineering, University of Technology, Technická 2896/2; 616 69, Brno; CZ, rehak@fme.vutbr.cz 
system was assembled from the IMC measuring device and shaft speed sensor. The main part of the measuring system included a contactless data transfer device. The input sensor was a strain gauge for value recording of the driving torque. The powertrain was modified as shown in Fig. 1. There are placed speed sensor and device for torque measurement. The data from these two devices was monitored and measurements were synchronized only when data was processed. A script for processing was created in the Matlab software. Measurement was created for driving uphill with varying grade. This article describes driving uphill with defined $6 \%$ grade. As mentioned, a non-contact device for torque measuring was used. The reason was that the shaft rotates while vehicle drives, and it is not possible to connect the strain gauge to the measuring device using a wire. Therefore, contactless equipment was used. This device was lent from its developers and it is not possible to provide more detailed information. During measurements, the engine speed was increased and vehicle was drove uphill. The evaluated data is shown in Figure 3.

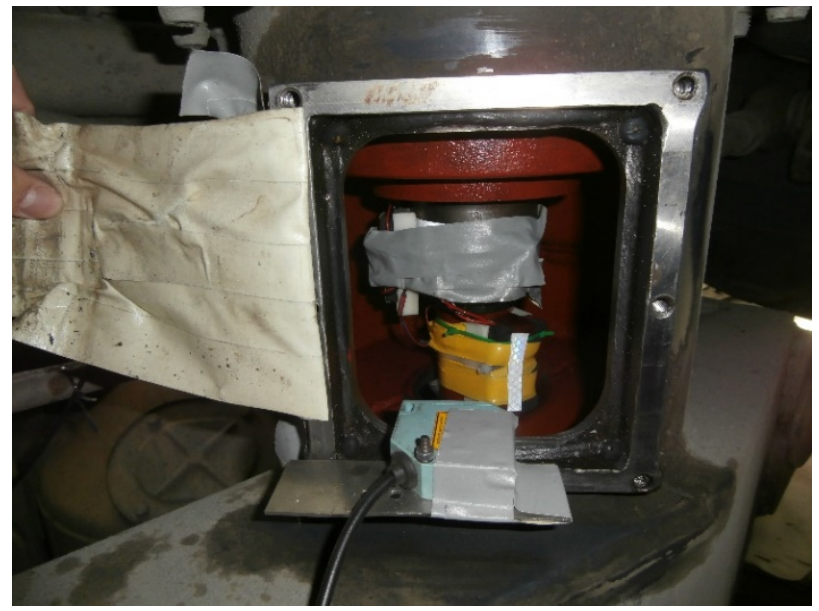

Fig. 1: Powertrain with sensors and module.

\section{Computational model}

The measurements were used to verify the computational model of the vehicle shown in Fig. 2. The computational model describes a vehicle with $8 \times 8$ drive and is assembled from own blocks described in Kučera (2015). The user can assemble different vehicle types and simulate vehicle dynamics, test mechatronic systems and analyse vibrations. Basic blocks were created with reference to Gillespie (1992) and Budynas (2015). In this article, the computational model is assembled from blocks describing the behaviour of the engine, clutch, gearbox, differential, drive shafts, brakes, tyre models, and block describing vehicle dynamics in the longitudinal direction. The whole model of the vehicle is assembled in Simulink software. The basic parameters of the vehicle are weight of $36000 \mathrm{~kg}$, engine power of $325 \mathrm{~kW}$ at $1800 \mathrm{rpm}$ and engine torque of $2100 \mathrm{Nm}$ at $1100 \mathrm{rpm}$

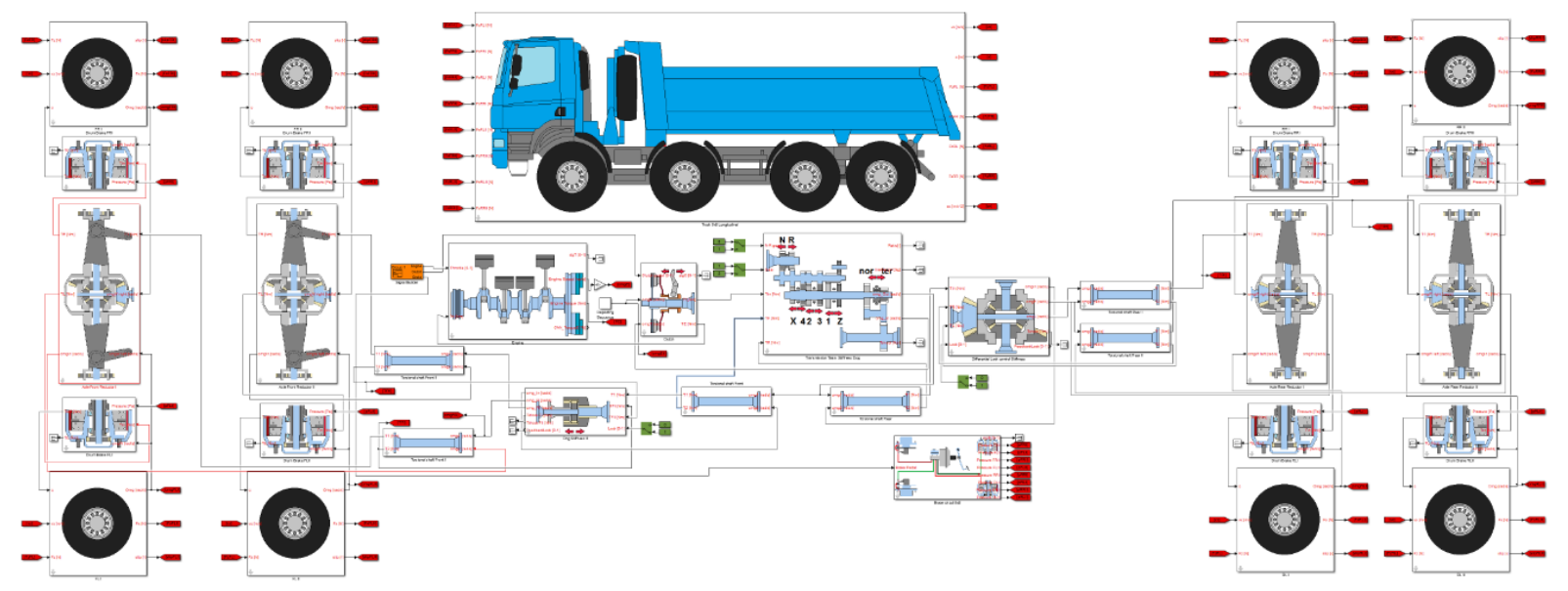

Fig. 2: Computational model of the vehicle with $8 \times 8$ drive. 
Data from the measurement was used for simulation of the vehicle driving and torque analyse. Engine speed was the input for the vehicle computational model to imitate the real drive. The required vehicle parameters were set to the computational model and an uphill driving was simulated with $6 \%$ grade. The lowest gear was set during simulation and it corresponds to real driving. The evaluated results are shown in Fig. 3. This simulation is limited because the influence of engine combustion cycles was not used. This is caused by the use of the engine speed from the measurement as an input. Therefore, the engine block generates only a revolution. This makes possible to compare the results only in the form of a mean value.

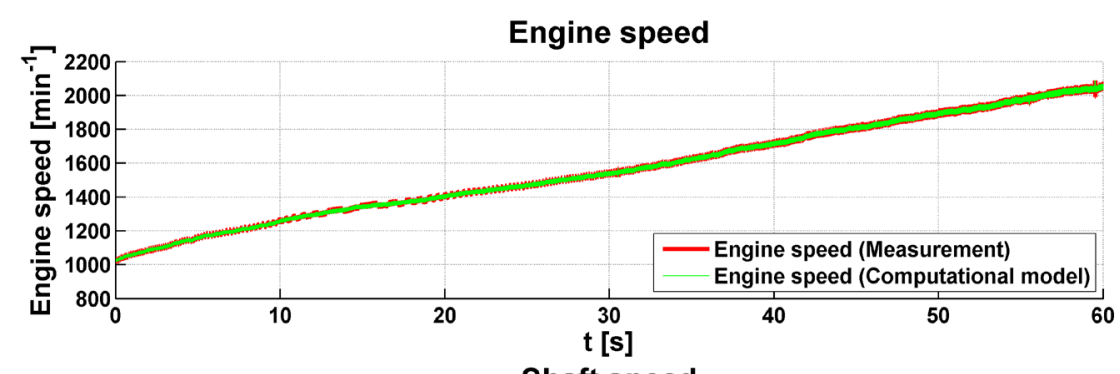

Shaft speed

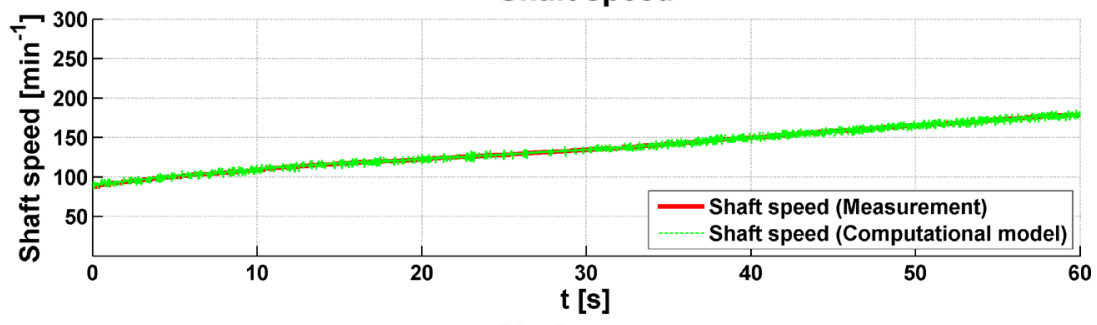

Shaft torque

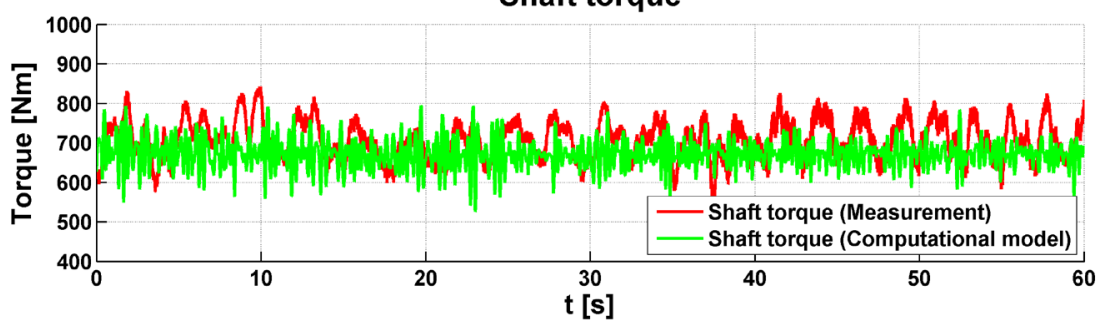

Fig. 3: Measured and simulated data of the truck powertrain

\section{Torque and torsional vibration}

Measurements and simulations were used to compare the torque. In both cases, the vehicle went uphill with $6 \%$ grade. Fig. 3 shows three graphs. The first graph compares engine speeds that were the same for both cases. The second graph compares the speed of the analysed shaft, it is also the same. And the third most important graph compares the torques from measurement and simulation. As mentioned above, the effects of torsional excitation by the diesel engine are not reflected in the simulation. Therefore, it is not possible to compare the shapes of the torque curves. But it is possible to compare the mean values and the results show that they are comparable. This mean torque corresponds to the load by grade of road. Therefore, the torque value can be verified by analytical calculation. To compare the torque shapes, it would be necessary to control the simulation in a different way. For example, this is the use of a PID regulator that would control the required speed by changing the accelerator pedal signal for the engine block.

Another solution step was the analysis of torsional vibrations. Works by Tưma (2014) and Drápal (2016) were used for their processing. From the measured data, an FFT analysis was performed for each engine speed. Then the whole spectrum was generated. This is shown in Fig. 4. The graph shows powertrain parts that influence the torsional vibration of the powertrain. The results show a partly 2 nd and significantly 4th harmonic order of engine speed. This corresponds to that type of diesel engine. The important components of this spectrum are the 1st and 2 nd harmonic order of the tyre speed. This harmonic orders are created by large segments of the tyre. The non-significant components of the spectrum are the 1 st harmonic order of the shaft speed (Shaft) and the gearing frequency of some mechanical gear (Axle). It is shown in Fig. 4. 


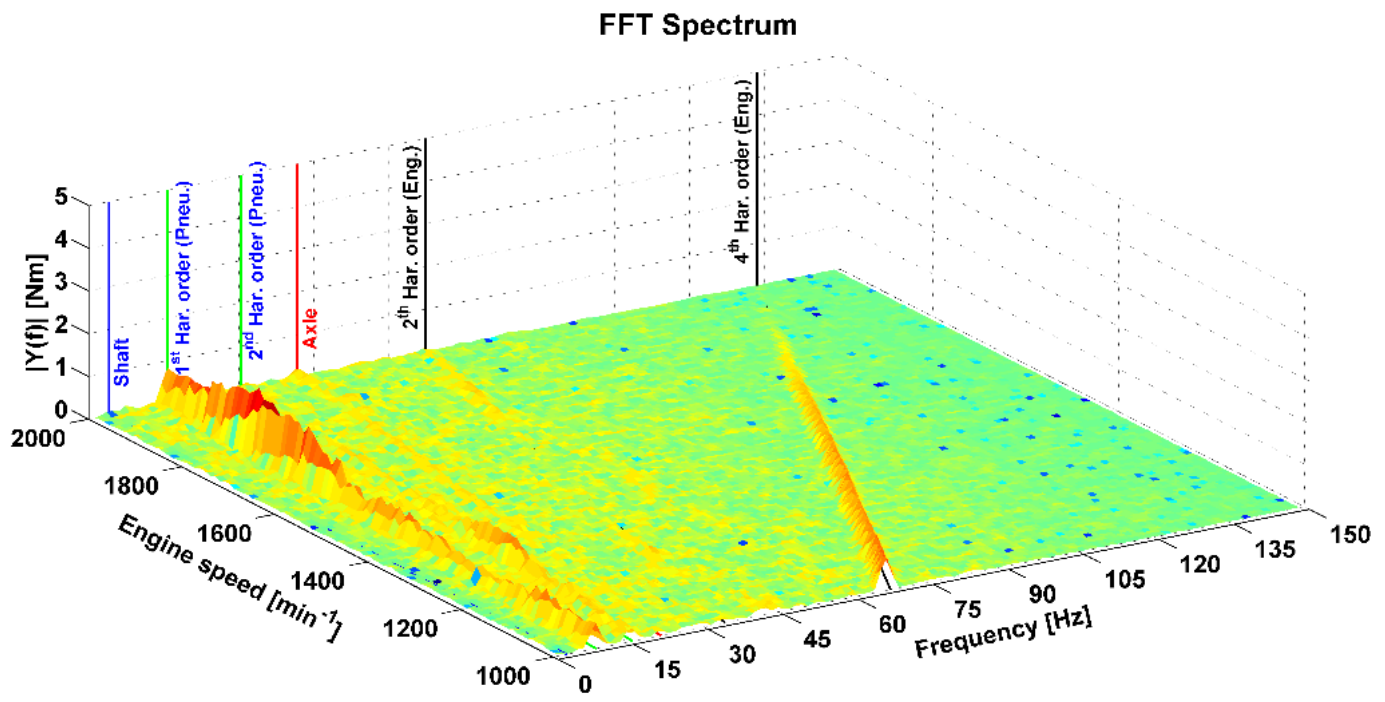

Fig. 4: Results of FFT analysis of the torque

\section{Conclusions}

Appropriate powertrain analysis for vibration reduction can be created for the development of new vehicles that will be more comfortable and able to compete with other companies. Therefore, it is still important to create new tools and methods for analysing the powertrain.

This article deals with the use of some custom tools for the analysis of the powertrain and its vibration. The first measurement of the vehicle powertrain was carried out and then compared with the vehicle computational model. The comparison was for uphill driving with $6 \%$ grade. The results show that the torques are comparable in terms of mean value. Other procedures have been proposed to compare the torque shape but this will be done in further research.

The second analysis focused on torsional vibrations. For their evaluation, FFT analysis was used to create a full spectrum including the engine speed range of 1000 to $2000 \mathrm{rpm}$. The harmonic orders of the engine speed, the harmonic orders of the tyre speed and the less significant harmonic order of the analysed shaft speed are visible in the spectrum. In the spectrum, the gear frequency is also visible. This article continues with research of the same shaft of the first study (Kučera, 2017) and there was problem with 1st harmonic order of shaft speed, therefore, it can be said that the torsional vibration corresponding to 1 st harmonic order of shaft speed is negligible. Overall, torsional vibrations have a negligible effect on the overall vibration of the vehicle. This was already indicated in (Kučera, 2017).

\section{Acknowledgement}

This work is an output of the internal BUT research project Reg. No. FSI-S-17-4104.

\section{References}

Budynas, R. G. and Nisbett, J. K. (2015) Shigley's mechanical engineering design. McGraw-Hill Education, New York.

Drápal, L. Šopík, L. and Vopařil, J. (2016) Investigation of torsional vibration of unconventional crank train. Vibroengineering Procedia, 7, pp. 31-36.

Gillespie, T. D. (1992) Fundamentals of Vehicle Dynamics. Society of Automotive engineers, Warrendale.

Kučera, P. (2015) Mechatronic approach to vehicle dynamics. Doctoral thesis, BUT Brno.

Kučera, P. and Pištěk, V. (2017) Truck vibrations caused by rotating shaft deflection. Journal of Vibroengineering, 19, 7, pp. 5361-5373.

Tůma, J. (2014) Vehicle gearbox noise and vibration: measurement, signal analysis, signal processing and noise reduction measures. Wiley, Chichster. 